\title{
Successful treatment of a child with vascular pythiosis
}

Tavitiya Sudjaritruk ${ }^{1}$, Virat Sirisanthana ${ }^{1,2^{*}}$

\begin{abstract}
Background: Human pythiosis is an emerging and life-threatening infectious disease caused by Pythium insidiosum. It occurs primarily in tropical, subtropical and temperate areas of the world, including Thailand. The aim of this report is to present the first pediatric case of typical vascular pythiosis.

Case Presentation: A 10-year-old boy with underlying $\beta$-thalassemia presented with gangrenous ulcers and claudication of the right leg which were unresponsive to antibiotic therapy for 6 weeks. Computerized tomography angiography indicated chronic arterial occlusion involving the right distal external iliac artery and its branches. High-above-knee amputation was urgently done to remove infected arteries and tissues, and to stop disease progression. Antibody to $P$. insidiosum was detected in a serum sample by the immunoblot and the immunochromatography tests. Fungal culture followed by nucleic sequence analysis was positive for $P$. insidiosum in the resected iliac arterial tissue. Immunotherapeutic vaccine and antifungal agents were administered. The patient remained well and was discharged after 2 months hospitalization without recurrence of the disease. At the time of this communication he has been symptom-free for 2 years.

Conclusions: The child presented with the classical manifestations of vascular pythiosis as seen in adult cases. However, because pediatricians were unfamiliar with the disease, diagnosis and surgical treatment were delayed. Both early diagnosis and appropriate surgical and medical treatments are crucial for good prognosis.
\end{abstract}

\section{Background}

Pythiosis is a life-threatening infectious disease occurring in humans and animals. The etiologic agent of the disease is Pythium insidiosum, an aquatic fungus-like organism (kingdom Chromista, phylum Oomycota, class Oomycetes), having an ecologic preference for swampy areas and found primarily in tropical, subtropical and temperate areas of the world [1-3].

Human pythiosis was first reported from Thailand in 1985 [4]. There are 4 different clinical forms of human pythiosis: vascular, ocular, cutaneous/subcutaneous and miscellaneous forms which account for 59, 33, 5, and $3 \%$ of all reported cases, respectively. All except the ocular form have been associated with patients who have underlying hematological diseases [2,3,5]. Human pythiosis is rare in children. Only a few well-documented cases have been reported, all of which were the

\footnotetext{
* Correspondence: vsirisan@med.cmu.ac.th

'Department of Pediatrics, Faculty of Medicine, Chiang Mai University,

Chiang Mai, Thailand

Full list of author information is available at the end of the article
}

cutaneous/subcutaneous form [6-8]. Human pythiosis has significant morbidity and mortality [2-5] because clinical information and diagnostic tools are limited, leading to under-recognition and under-diagnosis of the disease. Both early diagnosis and appropriate treatment are crucial for good prognosis. In this report, we described the first case of typical vascular pythiosis in a child in whom therapy was successful.

\section{Case presentation}

A 10-year-old boy who had had a splenectomy for his underlying $\beta$-thalassemia was admitted to the Chiang Mai University (CMU) Hospital for a gangrenous ulcer on his right leg and claudication. Six weeks prior to admission, he first noticed a small pustular lesion on his right ankle which later spontaneously ruptured and became an ulcer. There was no previous history of trauma. The patient reported frequently working in a rice field with his parents. He was brought to a local hospital where the diagnosis of pyomyositis was made. Incision and drainage were performed and his symptoms 
improved. Two weeks prior to admission another pustular lesion developed on his right shin which finally became a gangrenous ulcer. His other symptoms were fever, severe resting pain, intermittent claudication and swollen right knee. He was transferred to a district hospital where an ultrasound showed thrombosis of the right femoral and popliteal artery and enlarged lymph nodes at the right popliteal fossa. Arthrocentesis of the right knee revealed 855,000 cells $/ \mathrm{mm}^{3}$ of WBC (polymorphonuclear cell 74\%, mononuclear cell $26 \%$ ). He was diagnosed as having septic arthritis. Intravenous cloxacillin was given and the patient was transferred to the CMU Hospital.

Physical examination at the CMU Hospital revealed old ulcerated scars on the right shin and ankle (Figure 1), marked tenderness along the right leg, cool skin, diminished pulses of the right femoral and popliteal arteries, and absence of pulses of the right posterior tibialis and dorsalis pedis arteries. Computerized tomography angiography (CTA) showed occlusion of the lower third of the right external iliac artery, as well as

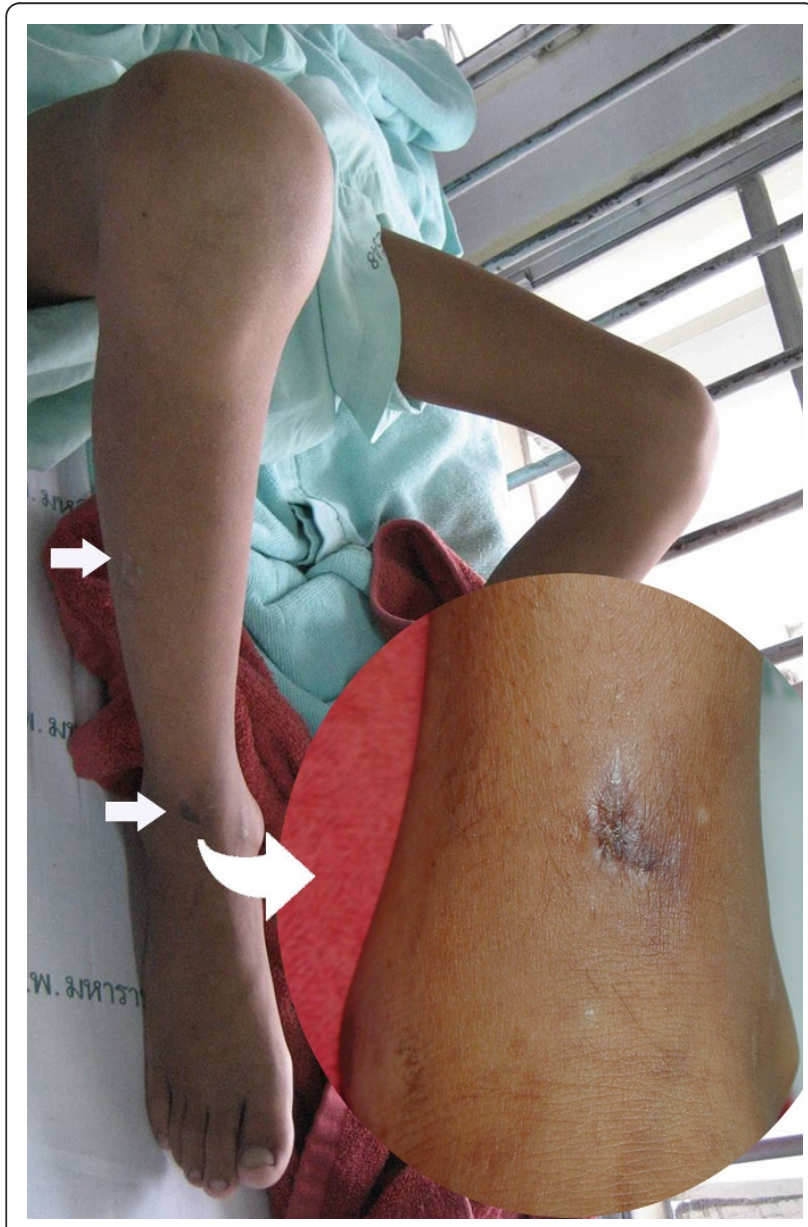

Figure 1 Ulcerated scar on the right ankle and shin. the right common femoral, superficial femoral, popliteal, anterior tibial, tibioperonial, peroneal and dorsalis pedis arteries (Figure 2). Multiple collateral vessels were seen around the right knee. He was diagnosed as a case of vascular pythiosis and had a high-above-knee amputation of his right leg.

Antibody to $P$. insidiosum was detected in a serum sample by immunoblot and immunochromatography tests (ICT). Fungal culture followed by nucleic sequence analysis of $18 \mathrm{~S}$ rRNA [9] was positive for P. insidiosum in the resected iliac arterial tissue. The tissue histopathology revealed evidence of chronic vasculitis with granulation tissue and thrombus on the anterior tibialis and the posterior tibialis up to the proximal margin of femoral arteries, but the special stains failed to demonstrate any etiologic agent, including Pythium spp.

After the surgery, the patient was given $P$. insidiosum immunotherapeutic vaccine (provided by Ariya Chindamporn, Chulalongkorn University, Bangkok; CUH Lot 140207/15-302), as well as the antifungal drugs,

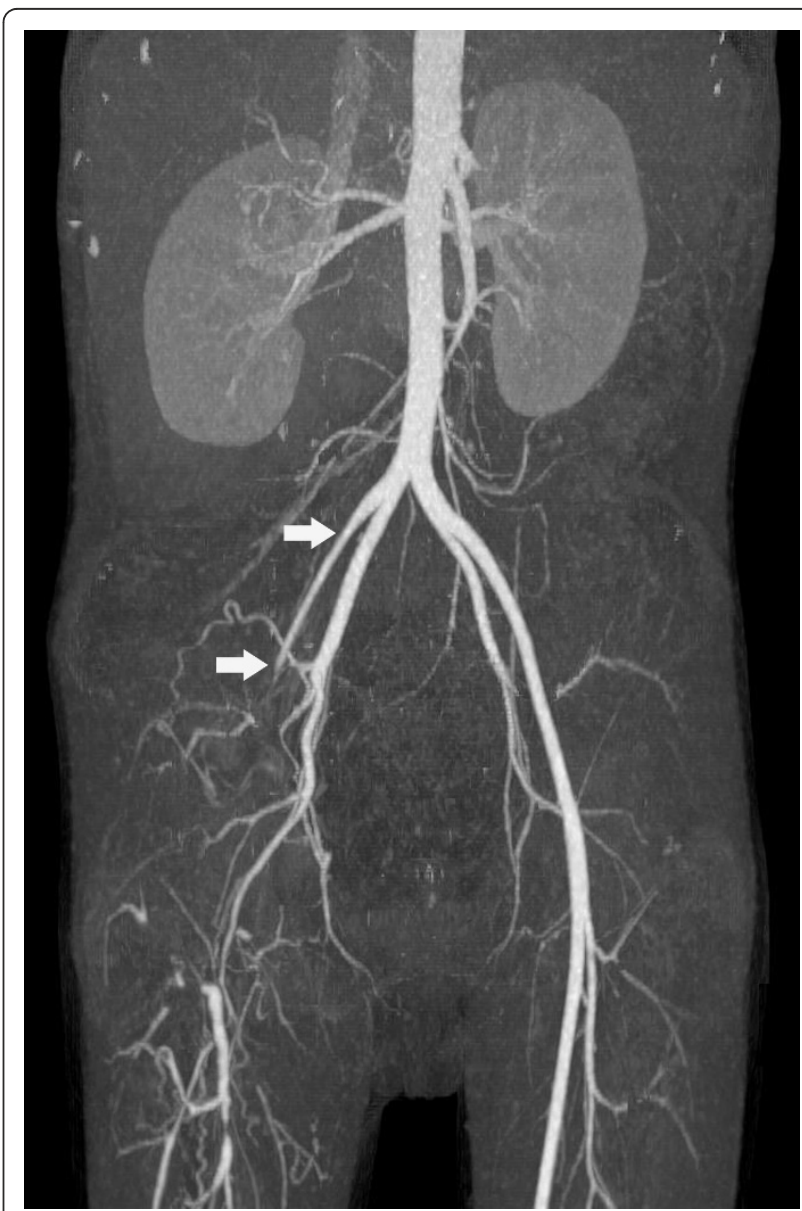

Figure 2 Computerized tomography angiography of the lower extremities showed occlusion of the lower third of the right external iliac artery and its branches. 
terbinafine at a dosage of $125 \mathrm{mg}$ twice daily $(13 \mathrm{mg} / \mathrm{kg} /$ day) and itraconazole at a dosage of $80 \mathrm{mg}$ twice daily $(8 \mathrm{mg} / \mathrm{kg} /$ day) for 2 months. The patient remained well and was discharged after almost 2 months after admission. Follow-up CTA performed 10 weeks after the amputation did not reveal recurrence of the disease. At the time of this communication, the patient has been symptom-free for 2 years.

\section{Conclusions}

We report a case of thalassemic boy with vascular pythiosis who was successfully treated by surgery together with $P$. insidiosum immunotherapeutic vaccine and antifungal therapy.

Many cases of human pythiosis have been reported from Thailand [2-5]. Most cases were males between 20-60 years of age, working in agriculture [2,3]. Virtually all vascular pythiosis patients usually present with chronic arterial insufficiency syndrome of the lower extremities, which varies from intermittent claudication to gangrenous ulceration [2,3]. A history of exposure to a swampy area prior to the illness is common. Patients usually have underlying hematological diseases, most frequently thalassemia or paroxysmal nocturnal hemoglobinuria [2,3,5]. A typical vascular pythiosis has never been reported in a pediatric patient. Our child presented with the classical manifestations of vascular pythiosis as seen in adult cases. However, because pediatricians were unfamiliar with the disease, diagnosis and surgical treatment were delayed. If a timely diagnosis had been made, he could have been treated by a below-knee amputation which is associated with a much better post-operative function.

Culture identification of $P$. insidiosum is a definite diagnostic method for pythiosis [3]. P. insidiosum can be cultured and grows very fast in conventional nutrient agar for fungus. An induction of the zoospore formation is needed to confirm the identity of the organism [10]. However in cases of vascular pythiosis, the fungal culture is usually negative because viable fungus is only present at the advancing edge of the diseased artery which is difficult for the surgeon to obtain $[1,2,4,10]$. Among available serologic tests, all except the immunodiffusion test have high levels of sensitivity and specificity. The advantage of ICT and hemagglutination over other serological tests is that these tests are user-friendly and rapid [11-15]. PCR amplification and identification of the 18s rRNA gene of $P$. insidiosum are also useful for organism identification in both the clinical specimens and culture specimens $[9,16]$.

Imaging studies, such as angiography and CTA, usually demonstrate an occlusion or aneurysm in medium-to-large-sized arteries of the lower extremities and trunk. They may also appear in collateral arteries due to the chronic course of the disease [2,3]. Histopathological studies may reveal fungal hyphae invading the arterial wall, with eosinophil infiltration, focal suppurative granuloma, as well as a blood clot containing hyphae in the arterial lumen [2]. Our patient presented with typical symptoms of vascular pythiosis. Antibody to $P$. insidiosum was detected by both the ICT and immunoblot methods. Fungal culture was positive for P. insidiosum in the resected iliac arterial tissue. His CTA study showed typical findings of vascular pythiosis. Although the histopathology of the surgical tissue of our case did not demonstrate any fungal hyphae, there was evidence of occlusion with a blood clot in the iliac artery.

Human pythiosis has a significant morbidity and mortality [2-5] because most healthcare professionals are not familiar with this rare organism and disease. Krajaejun et al. found that the overall mortality rate of human pythiosis was $29 \%$, and increased to $40 \%$ in its vascular form [2]. Successful management of human pythiosis requires early recognition and appropriate treatment. In vascular pythiosis, surgical removal of the infected arteries, aneurysms, and surrounding tissues should be urgently carried out. Most cases undergo limb amputation $[2,3]$ with careful attention paid to achieving an organism-free surgical margin. Because Pythium spp. does not possess ergosterol in its cytoplasmic membrane, conventional antifungal agents are ineffective for treatment of human pythiosis. However, there was one report of successful treatment of invasive facial pythiosis with two antifungal agents, namely terbinafine plus itraconazole [6]. Echinocandins, the new antifungal agents which inhibit the $\beta$-glucan synthesis of the cell wall of $P$. insidiosum, may be effective in the treatment of pythiosis [17]. An immunotherapeutic vaccine is another treatment option and favorable outcomes have been observed in humans [18].

In summary, human pythiosis is common in Thailand. It has high rates of morbidity and mortality. Early recognition requires the physician's awareness of the disease, especially in people with predisposing factors. Timely diagnosis and prompt treatment improve the prognosis.

\section{Consent}

Written informed consent was obtained from the parents of the patient for publication of this case report and any accompanying images. A copy of the written consent is available for review by the Editor-in-Chief of this journal.

\section{Acknowledgements}

The authors would like to thank Nongnuch Vanittanakom, Dr.rer.nat., Professor of Microbiology, Department of Microbiology, Faculty of Medicine, Chiang Mai University, Chiang Mai, Thailand for performing the organism identification. The authors also thank Ariya Chindamporn, Ph.D. of 
Microbiology, Associated Professor of Microbiology, Department of Microbiology, Faculty of Medicine, Chulalongkorn University, Bangkok, Thailand for the immunotherapeutic vaccine and H. Peter Lange, Research Institute for Health Sciences, Chiang Mai University, Chiang Mai, Thailand for help with the English manuscript.

\section{Author details}

'Department of Pediatrics, Faculty of Medicine, Chiang Mai University, Chiang Mai, Thailand. ${ }^{2}$ Research Institute for Health Sciences, Chiang Mai University, Chiang Mai, Thailand.

\section{Authors' contributions}

TS and VS provided the clinical care of the reported patient and were involved in drafting the manuscript. Both provided the corresponding figures. All authors read and approved the final version of the manuscript.

\section{Competing interests}

The authors declare that they have no competing interests.

Received: 3 September 2010 Accepted: 29 January 2011

Published: 29 January 2011

\section{References}

1. Mendoza L, Ajello L, McGinnis MR: Infection caused by the Oomycetous pathogen Pythium insidiosum. J Mycol Med 1996, 6:151-164.

2. Krajaejun T, Sathapatayavongs B, Pracharktam R, Nitiyanant P, Leelachaikul P, Wanachiwanawin W, et al: Clinical and epidemiological analyses of human pythiosis in Thailand. Clin Infect Dis 2006, 43:569-576.

3. Krajaejun T, Sathapatayavongs B, Chaiprasert A, Srimuang S: Do you know human pythiosis. J Infect Dis Antimicrob Agents 2008, 25:45-51.

4. Thianprasit M, Chaiprasert A, Imwidthaya P: Human pythiosis. Curr Top Med Mycol 1996, 7:43-54.

5. Sathapatayavongs B, Leelachaikul P, Prachaktam R, Atichartakarn V, Sriphojanart S, Trairatvorakul P, et al: Human pythiosis associated with thalassemia hemoglobinopathy syndrome. J Infect Dis 1989, 159:274-280.

6. Shenep JL, English BK, Kaufman L, Pearson TA, Thompson JW, Kaufman RA, et al: Successful medical therapy for deeply invasive facial infection due to Pythium insidiosum in a child. Clin Infect Dis 1998, 27:1388-1393.

7. Triscott JA, Weedon D, Cabana E: Human subcutaneous pythiosis. J Cutan Pathol 1993, 20:267-271.

8. Rinaldi MG, Seidenfeld SM, Fotherbill AM, McGough DA: Pythium insidiosum causes severe disease in healthy boy. Mycol Observer 1989, 9:7.

9. Vanittanakom N, Supabandhu J, Khamwan C, Praparattanapan J, Thirach S, Prasertwitayakij $\mathrm{N}$, et al: Identification of emerging human-pathogenic Pythium insidiosum by serological and molecular assay-based methods. J Clin Microbiol 2004, 42:3970-3974.

10. Chaiprasert A, Samerpitak K, Wanachiwanawin W, Thasnakorn P: Induction of zoospore formation in Thai isolates of Pythium insidiosum. Mycoses 1990, 33:317-323.

11. Pracharktam R, Changtrakool P, Sathapatayavongs B, Jayanetra P, Ajello L: Immunodiffusion test for diagnosis and monitoring of human pythiosis insidiosi. J Clin Microbiol 1991, 29:2661-2662.

12. Krajaejun T, Kunakorn M, Niemhom S, Chongtrakool P, Pracharktam R: Development and evaluation of an in-house enzyme-linked immunosorbent assay for early diagnosis and monitoring of human pythiosis. Clin Diagn Lab Immunol 2002, 9:378-382.

13. Krajaejun $T$, Kunakorn $M$, Pracharktam $R$, Chongtrakool $P$, Sathapatayavongs B, Chaiprasert A, et al: Identification of a novel 74kiloDalton immunodominant antigen of Pythium insidiosum recognized by sera from human patients with pythiosis. J Clin Microbiol 2006, 44:1674-1680.

14. Jindayok T, Piromsontikorn S, Srimuang S, Khupulsup K, Krajaejun T: Hemagglutination test for rapid serodiagnosis of human pythiosis. Clin Vaccine Immunol 2009, 16:1047-1051.

15. Krajaejun T, Imkhieo S, Intaramat A, Ratanabanangkoon K: Development of an immunochromatographic test for rapid serodiagnosis of human pythiosis. Clin Vaccine Immunol 2009, 16:506-509.

16. Grooters AM, Gee MK: Development of a nested polymerase chain reaction assay for the detection and identification of Pythium insidiosum. J Vet Intern Med 2002, 16:147-152.
17. Cavalheiro AS, Maboni G, de Azevedo MI, Argenta JS, Pereira DI, Spader T, et al: In Vitro activity of terbinafine combined with caspofungin and azoles against Pythium insidiosum. Antimicrob Agents Chemother 2009, 53:2136-2138

18. Wanachiwanawin W, Mendoza L, Visuthisakchai S, Mutsikapan P, Sathapatayavongs B, Chaiprasert A, et al: Efficacy of immunotherapy using antigens of Pythium insidiosum in the treatment of vascular pythiosis in humans. Vaccine 2004, 22:3613-3621.

\section{Pre-publication history}

The pre-publication history for this paper can be accessed here: http://www.biomedcentral.com/1471-2334/11/33/prepub

doi:10.1186/1471-2334-11-33

Cite this article as: Sudjaritruk and Sirisanthana: Successful treatment of a child with vascular pythiosis. BMC Infectious Diseases 2011 11:33.

\section{Submit your next manuscript to BioMed Central and take full advantage of:}

- Convenient online submission

- Thorough peer review

- No space constraints or color figure charges

- Immediate publication on acceptance

- Inclusion in PubMed, CAS, Scopus and Google Scholar

- Research which is freely available for redistribution

Submit your manuscript at www.biomedcentral.com/submit
Ciomed Central 